\title{
Facile Preparation of Charcoal Nanomaterial from Fishery Waste with Remarkable Adsorption Ability
}

\author{
Yaning Wang ${ }^{1}$, Yarui Zhou ${ }^{2}$, Lu Cai ${ }^{3}$, Jian Guo ${ }^{4}$, Yong Xu ${ }^{5}$, Hailong Zhang ${ }^{1, *}$, Lili Ji ${ }^{1, *}$ and \\ Wendong Song ${ }^{6}$ \\ 1 Institute of Innovation \& Application, Zhejiang Ocean University, Zhoushan 316022, China; \\ wynzjou@126.com \\ 2 School of Naval Architecture and Mechanical-Electrical Engineering, Zhejiang Ocean University, Zhoushan \\ 316022, China; zyr0612Z@gmail.com \\ 3 College of Environmental and Science Technology, Donghua University, Shanghai 201620, China; \\ cailu@zjou.edu.cn \\ 4 College of Food and Medical, Zhejiang Ocean University, Zhoushan 316022, China; guojian@zjou.edu.cn \\ 5 Zhoushan National Oil Reserve Base Co., Ltd., Zhoushan 316022, China; xuyong@sinochem.com \\ 6 College of Petrochemical and Energy Engineering, Zhejiang Ocean University, Zhoushan 316022, China; \\ swd60@163.com \\ * Correspondence: zhanghailong@zjou.edu.cn (H.Z.); jillzjou@gmail.com (L.J.); Tel.: +86-0580-2262589 (L.J.); \\ Fax: +86-0580-2262063 (H.Z.)
}

Received: 26 March 2019; Accepted: 18 April 2019; Published: 23 April 2019

\begin{abstract}
In this study, modified activated fishbone charcoal (MAFC) was successfully prepared to remove emulsified oil from oily wastewater. Various characteristic techniques, including SEM, XRD, FTIR, and BET, were employed to investigate the morphology, texture, and surface properties of as-prepared samples. BET results demonstrated that the specific surface area of fishbone charcoal increased from $69.8 \mathrm{~m}^{2} / \mathrm{g}$ to $206.0 \mathrm{~m}^{2} / \mathrm{g}$ after treatment with $\mathrm{K}_{2} \mathrm{CO}_{3}$ as an activating agent, while the total pore volume of MAFC increased from $0.003 \mathrm{~cm}^{3} / \mathrm{g}$ to $0.3 \mathrm{~cm}^{3} / \mathrm{g}$, accompanied by the formation of abundant pore structures. It was observed that $90.1 \%$ of emulsified oil $(100 \mathrm{mg} / \mathrm{L})$ was successfully removed by MAFC under our experimental conditions. The results of a kinetic and isotherm model analysis indicated that the adsorption experimental data were not only consistent with the Langmuir adsorption isotherm but were also well-described by the pseudo-second-order adsorption model. It is expected that this highly efficient and inexpensive MAFC can be a promising bio-adsorbent for removing organic pollutants from industrial wastewater.
\end{abstract}

Keywords: fishbone charcoal; modification; adsorption capacity; removal efficiency

\section{Introduction}

Oily wastewater can impact on the environment in negative and harmful ways and may result in serious environmental pollution. There are many sources of oily wastewater, including accidental marine oil spill, wastewater from oil exploitation and oil tank cleaning, and ballast water. The direct discharge of oily wastewater will severely threaten human health and lead to long-term ecological environmental distress [1,2]. There are many technologies available for the treatment of oily wastewater, which can be divided into three categories: mechanical, chemical, and biological treatment methods [3-7]. Nevertheless, these techniques have several limitations, such as secondary pollution to the environment, a complicated operation process, high costs, and high time consumption. Traditionally, adsorption has been the preferred method for researchers due to its emulsification degree and its size of oil droplets in oily wastewater $[8,9]$. 
Porous biochar materials are a promising solution because of their large surface area, abundant pore structure, the hydrophobic nature of their surface, and their mechanical and thermal stability [10-13]. In recent decades, it has been noted worldwide that biochar materials can be utilized as an adsorbent. Jian and co-workers have studied the adsorption property of biochars derived from rice husk, which has a high adsorption capacity for methylene blue, iodine, and copper ions from aqueous solution, due to its ion-exchange and complexation properties [14]. Various biochars pyrolyzed at $700{ }^{\circ} \mathrm{C}$ were obtained for the removal of organic contaminants. Correlations between the adsorption behavior and the physicochemical properties of biochars were studied and analyzed, while the mechanism and driving forces responsible for adsorption were also explored [15]. Research on adsorption kinetics, isotherms, and thermodynamics, and the mechanism of adsorption of methylene blue (MB) has been conducted on biochar prepared from the co-pyrolysis of municipal sewage sludge and tea waste [16]. Results indicated that the interaction between $\mathrm{MB}$ and biochar involved electrostatic interaction, ion exchange, surface complexation, and physical interaction. A novel biochar-AlOOH nanocomposite with excellent adsorption capacities for various contaminants in aqueous solutions has also been developed [17]. Moreover, compared with other processing methods, the biochar adsorption method has many advantages, such as a small occupied area, high adsorption efficiency, easy operation, and good effluent quality, which can be effectively used for the advanced treatment of oily wastewater $[18,19]$. By adding biochar materials into emulsified oily wastewater, the experimental system will successfully realize a change from liquid to semi-solid, leading to an easier removal of emulsified oil from oily wastewater [20-23]. In particular, biomass wastes have become potential raw materials for the production of carbon nanostructures due to their abundant availability and environmental friendliness $[13,19]$. Waste fishbone is predominantly composed of inorganic compounds with a small number of organic compounds [24]. It is well known that hydroxyapatite $\left(\mathrm{Ca}_{10}\left(\mathrm{PO}_{4}\right)_{6}(\mathrm{OH})_{2}\right.$, $\mathrm{HAp}$ ) is the main component in inorganic porous substances and has outstanding adsorption properties by complexing with phosphate and hydroxyl groups $[25,26]$. For instance, Wang et al. investigated the adsorption performance of fishbone charcoal derived from grass carp fish on $\mathrm{Pb}$ (II) ion [27]. Ehab et al. suggested that fishbone biochar extracted from Mullet fish has a high adsorption capacity for the removal of hazardous heavy metals from wastewater [28]. Natural fishbone apatite has been prepared and can achieve its highest $\mathrm{Pb}$ removal rate of $24.76 \%$ when the ratio of fishbone to fly ash is $20 \%$, after a $72 \mathrm{~h}$ leaching process [29]. These studies have demonstrated that fishbone material may be an excellent and low-cost adsorbent for the removal of environmental pollutants. However, to our best knowledge, the utilization of fishbone for the preparation of oily wastewater adsorbent has not been reported elsewhere.

Chemical activation has been widely used as an effective method for producing excellent biochar materials with high surface areas and abundant pore structures. In general, the mechanism of chemical activation includes hydroxide reduction and carbon oxidation [30]. Other commonly used chemical reagents, such as $\mathrm{ZnCl}_{2}, \mathrm{KOH}$, and $\mathrm{NaOH}$, are hazardous, corrosive, and environmentally unfriendly, causing secondary pollution to the ecosystem [31-34]. Therefore, as a harmless, mild, and benign chemical substance, $\mathrm{K}_{2} \mathrm{CO}_{3}$ has gained many application prospects.

The main objective of this paper was to develop a novel fishbone charcoal nanomaterial and to assess its adsorption performance for removing emulsified oil from oily wastewater. In this study, we demonstrated the facile preparation of modified activated fishbone charcoal (MAFC) via a combination of pyrolysis and modification by $\mathrm{K}_{2} \mathrm{CO}_{3}$ impregnation. The effectiveness of this modified adsorbent for removing emulsified oil was investigated under various environmental conditions, with different adsorbent doses, contact times, contact temperatures, and initial oil concentrations. In addition, the structure, morphology, and surface properties of the synthesized samples were characterized by XRD, SEM, and FTIR. The unique features of MAFC indicated its great potential in the engineering field for environmental remediation. 


\section{Materials and Methods}

\subsection{Materials}

Waste fishbones were collected from a local food market in Zhoushan, Zhejiang. We purchased 0\# diesel oil from Zhoushan Petrochemical Co., Ltd., (Zhoushan, China). All the other inorganic and organic chemicals were of analytical grade and were obtained from Sinopharm Chemical Reagent Co., Ltd., Shanghai, China. All reagents used in the study were of analytical grade.

\subsection{Preparation of Fish Charcoal Material}

The collected fishbones were thoroughly washed several times with $100{ }^{\circ} \mathrm{C}$ distilled water, followed by drying at $120^{\circ} \mathrm{C}$ for $12 \mathrm{~h}$ in an oven. Then, $10 \mathrm{~g}$ dried fishbone was pre-carbonized at $750{ }^{\circ} \mathrm{C}$ for $2 \mathrm{~h}$ in nitrogen $(99.995 \%)$ flow $\left(100 \mathrm{~cm}^{3} / \mathrm{min}\right)$, with a temperature ramp of $10{ }^{\circ} \mathrm{C} / \mathrm{min}$. The carbonized fishbone (FBC) was allowed to cool to room temperature under $\mathrm{N}_{2}$ gas flow.

During activation, the resulting char was stirred in $\mathrm{K}_{2} \mathrm{CO}_{3}$ solution (the ratio of carbon to $\mathrm{K}_{2} \mathrm{CO}_{3}$ was $1: 3, \mathrm{wt} / \mathrm{wt} \%$ ) for $24 \mathrm{~h}$ and then activated in a vacuum tube furnace at $750{ }^{\circ} \mathrm{C}$ for $90 \mathrm{~min}$. The same temperature ramp and nitrogen flow were adopted for the pyrolysis process and activation experiment. The $\mathrm{K}_{2} \mathrm{CO}_{3}$-modified fishbone (MAFC) was washed with de-ionized water until the $\mathrm{pH}$ was adjusted to 7.0-7.2 and was then dried at $110^{\circ} \mathrm{C}$ in an oven for $3 \mathrm{~h}$, before being used in the following experiments.

\subsection{Characterization}

The composition and morphology of the samples were investigated by scanning electron microscopy (SEM, Hitachi S-4800, Tokyo, Japan) and X-ray diffraction (XRD, Ultima IV X-Ray Diffractometer, Rigaku Corporation, Tokyo, Japan) in the range of $2 \theta=10^{\circ}-80^{\circ}$. The surface functional groups before and after activation were analyzed by Fourier transform infrared spectra (FTIR, Nicolet 5700, Thermo Corp., Waltham, MA, USA). The specific surface areas of the samples were measured with a Micromeritics ASAP 2010 instrument and analyzed by the BET method.

\subsection{Adsorption Experiment}

Sorption performance of MAFC was investigated by testing the removal efficiency of emulsified oil from oily wastewater. The experimental system was synthesized by mixing 0\# diesel oil and distillated water for $30 \mathrm{~min}$ using ultrasound. Adsorption experiments were carried out in $100 \mathrm{~mL}$ Erlenmeyer flasks containing the initial oil concentration $(50 \mathrm{~mL})$, which ranged from $30 \mathrm{mg} / \mathrm{L}$ to $300 \mathrm{mg} / \mathrm{L}(100 \mathrm{mg} / \mathrm{L}$ for the adsorption kinetics study), then, $0.1 \mathrm{~g}$ MAFC was added into the flasks with an initial $\mathrm{pH}$ of 7. The mixtures were continuously shaken at $120 \mathrm{rpm}$ in a constant temperature oscillator for $30 \mathrm{~min}$. The residual oil concentration in the supernatant was analyzed by measuring light absorbance at a wavelength of $255 \mathrm{~nm}$ using an UV-Vis (UV-2250 Shimadzu, Tokyo, Japan) spectrometer [35]. Two possible key factors, adsorbent dose and reaction temperature, were investigated in several batch experiments.

The adsorption property of the samples was determined by using the following equation:

$$
\text { Adsorption capacity }(\mathrm{mg} / \mathrm{g})=\left(\mathrm{C}_{0}-\mathrm{C}_{\mathrm{e}}\right) \times(\mathrm{V} / \mathrm{m})
$$

where $\mathrm{q}_{\mathrm{e}}$ is the equilibrium adsorption capacity of samples, $\mathrm{mg} / \mathrm{g}, \mathrm{C}_{0}(\mathrm{mg} / \mathrm{L})$ is the initial concentration of the emulsified oil, $\mathrm{C}_{\mathrm{e}}(\mathrm{mg} / \mathrm{L})$ is the residual oil concentration in the supernatant, $\mathrm{V}$ is the volume of the solution, $\mathrm{L}$, and $\mathrm{m}$ is the mass of the adsorbent, $\mathrm{g}$.

$$
\text { Adsorption }=\left[\left(\mathrm{A}_{0}-\mathrm{A}_{1}\right) / \mathrm{A}_{0}\right] \times 100 \%
$$

where $\mathrm{R}$ is the removal percentage of emulsified oil, $\mathrm{A}_{0}$ is the initial absorbance of emulsified oil, and $\mathrm{A}_{1}$ is the absorbance measured at a definite time. 


\subsection{Recyclability Experiments}

Recyclability experiments were implemented to evaluate the efficiency of an as-prepared adsorbent. First, $0.1 \mathrm{~g}$ of MAFC was added to $50 \mathrm{~mL}$ of emulsified oil solution $(100 \mathrm{mg} / \mathrm{L})$ for $30 \mathrm{~min}$ of adsorption. Following centrifugation the MAFC was placed in an Erlenmeyer flask, and $25 \mathrm{~mL}$ of $\mathrm{n}$-hexane was added. This was followed by the process of desorption, for 30 minutes. At the end, the sample was dried in an oven at $60^{\circ} \mathrm{C}$ for $12 \mathrm{~h}$.

\subsection{Main Kinetics Models}

Main kinetics models were used to investigate the emulsified oil adsorption kinetics on the raw fishbone (RFB), FBC, and MAFC.

The adsorption kinetics modes were denoted by the following equation:

a. Pseudo-first-order model

$$
\operatorname{Ln}\left(\mathrm{q}_{\mathrm{e}}-\mathrm{q}_{\mathrm{t}}\right)=\ln \mathrm{q}_{\mathrm{e}}-\mathrm{k}_{1} \mathrm{t}
$$

where $\mathrm{q}_{\mathrm{e}}$ and $\mathrm{q}_{\mathrm{t}}$ are, respectively, the amounts of emulsified oil (mg/g) adsorbed at equilibrium and at time $t$. $K_{1}$ is the rate constant of the pseudo-first-order $\left(\mathrm{min}^{-1}\right)$.

b. Pseudo-second-order model

$$
\frac{\mathrm{t}}{\mathrm{q}_{\mathrm{t}}}=\frac{1}{\mathrm{~K}_{\mathrm{s}} \mathrm{q}_{\mathrm{e}}^{2}}+\frac{1}{\mathrm{q}_{\mathrm{e}}} \mathrm{t}
$$

where $\mathrm{q}_{\mathrm{e}}$ and $\mathrm{q}_{\mathrm{t}}$ are the amounts of emulsified oil $(\mathrm{mg} / \mathrm{g})$ adsorbed at equilibrium and at time $\mathrm{t}$, respectively. $\mathrm{K}_{\mathrm{s}}$ is the rate constant of the pseudo-second-order $\left(\mathrm{min}^{-1}\right)$.

\subsection{Adsorption Isotherms Models}

Thewo isotherm models used were denoted by the following equation:

I. Langmuir model

$$
\frac{\mathrm{C}_{\mathrm{e}}^{\prime}}{\mathrm{q}_{\mathrm{e}}^{\prime}}=\frac{1}{\mathrm{q}_{\max } \mathrm{b}}+\frac{1}{\mathrm{q}_{\max }} \mathrm{C}_{\mathrm{e}}^{\prime}
$$

II. Freundlich model

$$
\ln \mathrm{q}_{\mathrm{e}}^{\prime}=\ln \mathrm{K}_{\mathrm{f}}+\frac{1}{\mathrm{n}} \ln \mathrm{C}_{\mathrm{e}}^{\prime}
$$

where $C_{e}(m g / L)$ is the equilibrium concentration in the solution, $q_{e}(m g / g)$ is the emulsified oil adsorbed at equilibrium, $\mathrm{b}(\mathrm{mg} / \mathrm{g})$ is the maximum adsorption capacity, $\mathrm{n}$ is the Freundlich constant related to adsorption intensity, and $\mathrm{q}_{\max }(\mathrm{mg} / \mathrm{g})$ and $\mathrm{K}_{\mathrm{f}}\left((\mathrm{mg} / \mathrm{g})(\mathrm{L} / \mathrm{mg})^{1 / \mathrm{n}}\right)$ are the adsorption constants for Langmuir and Freundlich models, respectively.

\section{Results and Discussion}

\subsection{Characterization of Fishbone Nanomaterials}

Nitrogen adsorption isotherms and the pore size distribution (PSD) of MAFC are shown in Figure 1. It can be observed that the nitrogen adsorption isotherms of MAFC fit well with type IV isotherms, indicating the existence of both micropores and mesopores. The adsorption capacity of nitrogen increases rapidly with the increase of relative pressure after $\mathrm{p} / \mathrm{p}_{0}>0.4$, which suggests the existence of mesoporous structures. The pore size distribution of MAFC also exhibits a significant presence of mesopores, with pores mainly in the range $2-20 \mathrm{~nm}$. Specific surface area parameters of fishbone materials before and after activation are listed in Table 1. PSD and BET results indicate that $\mathrm{K}_{2} \mathrm{CO}_{3}$ activation of fishbone can produce a well-developed and evenly distributed porous structure. The high specific surface area and porous network of MAFC is conducive to increasing its adsorption capacity. 


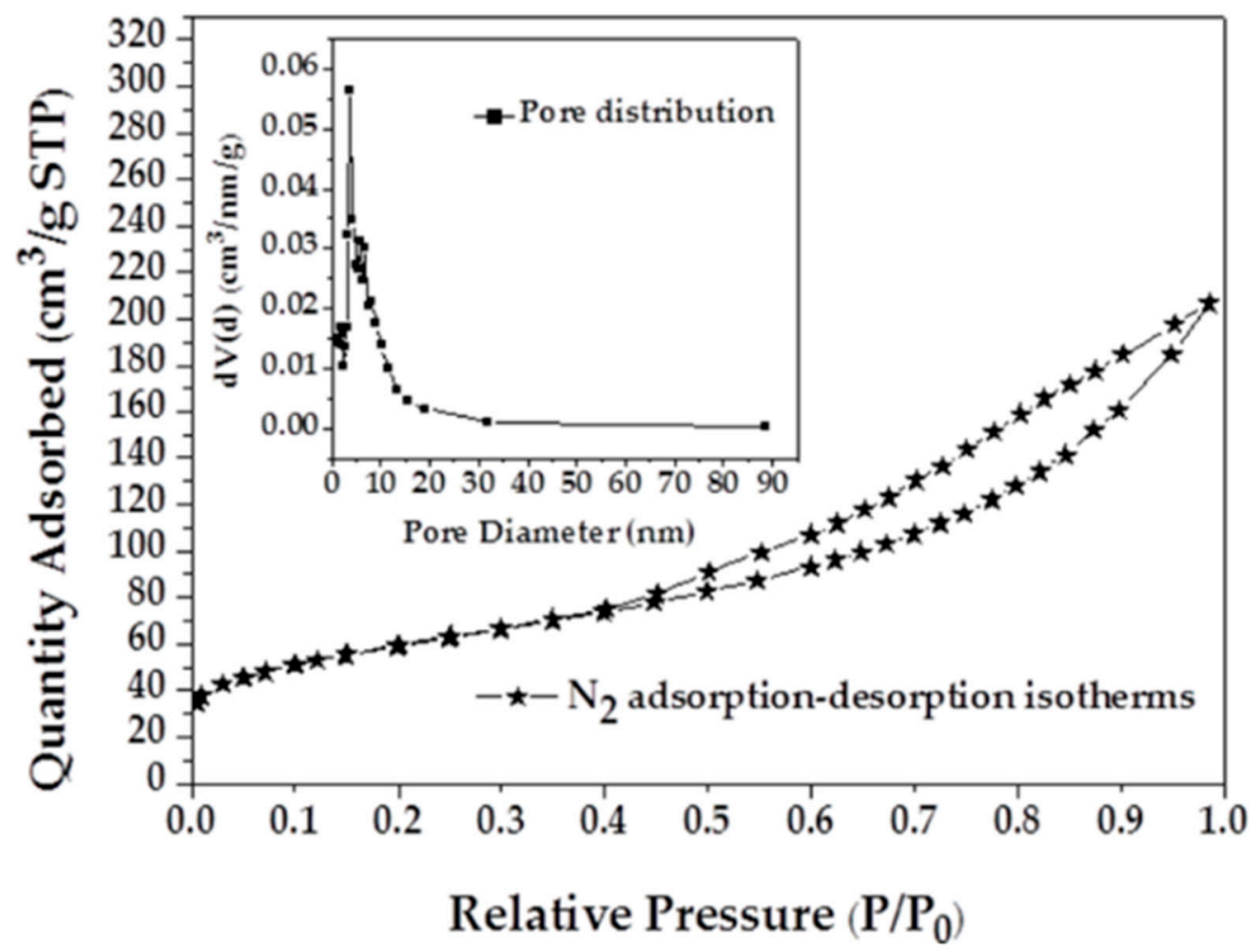

Figure 1. Nitrogen adsorption isotherms of modified activated fishbone charcoal (MAFC) with corresponding pore size distribution.

Table 1. Specific surface area parameters of fishbone charcoal.

\begin{tabular}{cccc}
\hline Fishbone Materials & $\begin{array}{c}\text { BET } \\
\left(\mathbf{m}^{\mathbf{2}} \mathbf{/ g}\right)\end{array}$ & $\begin{array}{c}\text { Total Pore Volumes } \\
\mathbf{( \mathbf { c m } ^ { 3 } / \mathbf { g } )}\end{array}$ & $\begin{array}{c}\text { Average Pore Diameter } \\
\mathbf{( n m})\end{array}$ \\
\hline raw fishbone & 0.7 & 0.003 & 5.5 \\
FBC & 69.8 & 0.192 & 10.8 \\
MAFC & 206.0 & 0.3 & 6.2 \\
\hline
\end{tabular}

As shown in Table 1, the pore structure was significantly improved via pyrolysis and the modification of $\mathrm{K}_{2} \mathrm{CO}_{3}$ impregnation. BET results of fishbone materials showed an increase from 0.7 to $206.0 \mathrm{~m}^{2} / \mathrm{g}$, indicating abundant active sites, and an increase in the binding sites for organic molecules or pollutants, i.e., a significant increase in the adsorption activity of adsorbent [36]. It is presumed that the potassium compound could promote gasification to widen the existing pore structures and create new pores during the activation process [37], according to the following reactions (7-9) [38,39]:

$$
\begin{gathered}
\mathrm{K}_{2} \mathrm{CO}_{3}+2 \mathrm{C} \rightarrow 2 \mathrm{~K}+3 \mathrm{CO} \\
\mathrm{K}_{2} \mathrm{CO}_{3} \rightarrow \mathrm{K}_{2} \mathrm{O}+\mathrm{CO}_{2} \\
\mathrm{~K}_{2} \mathrm{O}+2 \mathrm{C} \rightarrow 2 \mathrm{~K}+\mathrm{CO}
\end{gathered}
$$

Figure 2 illustrates surface morphologies of RFB, FBC, and MAFC samples visualized using SEM. It can be seen from Figure $2 \mathrm{a}$ that raw fishbone has a very smooth and clean surface without impurities or debris attached. In Figure 2b, FBC exhibits an uneven structure, which confirms the presence of heterogeneous porous structures, and a small amount of tiny crystal structures with an average diameter of 20-400 nm appear on the surface of FBC. After further modification, the surface of MAFC (Figure 2c,d) appeared to have a more porous structure and was much rougher than other as-prepared samples. The results demonstrated that the internal structures of MAFC were further opened and 
exposed after impregnation with $\mathrm{K}_{2} \mathrm{CO}_{3}$, which increased the number of adsorption sites in MAFC, and was beneficial to the adsorption performance of MAFC.

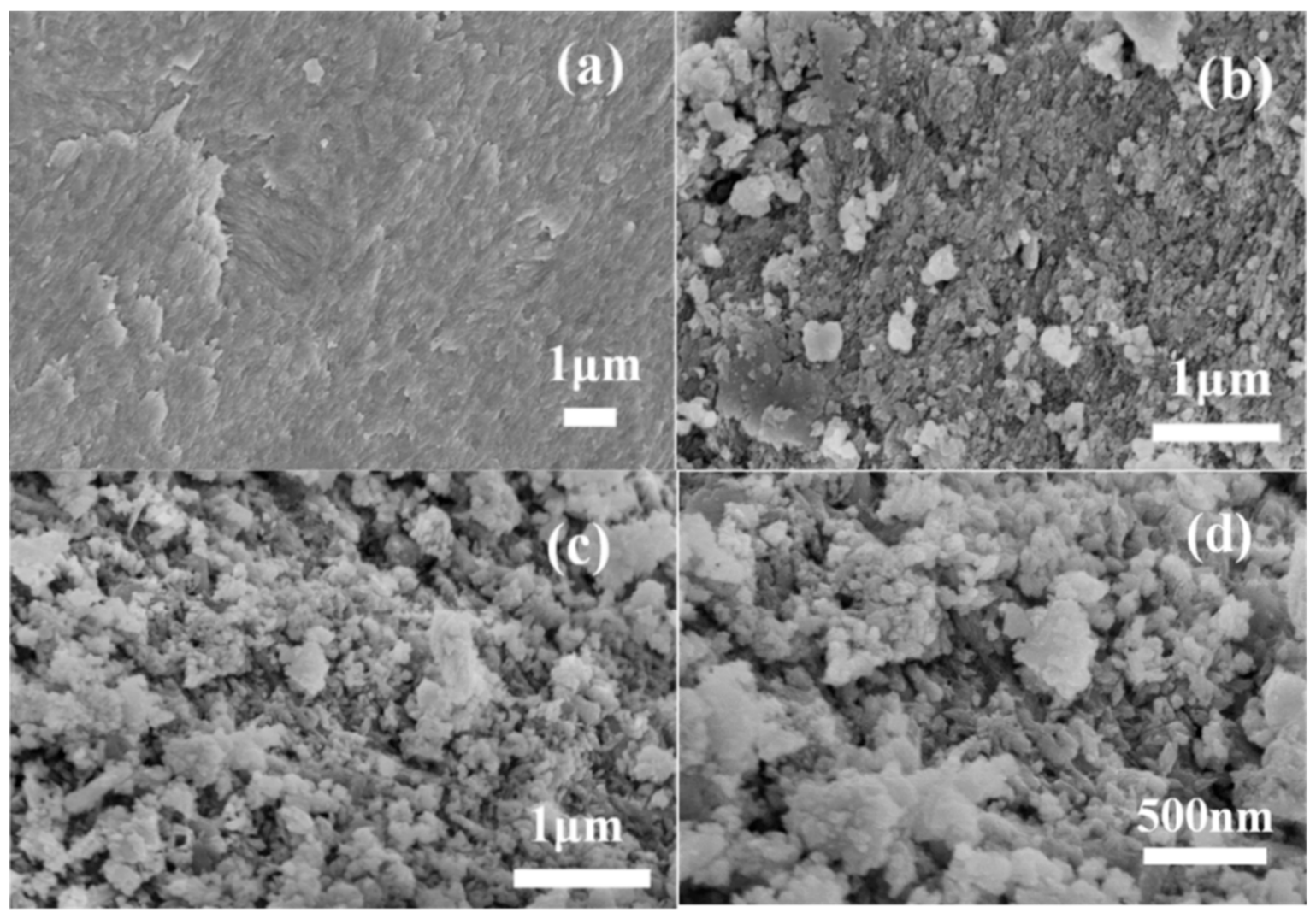

Figure 2. Surface morphologies of raw fishbone (RFB) (a), carbonized fishbone (FBC) (b), and MAFC with different magnifications (c,d).

The crystalline structure and the purity of as-prepared samples were assessed using X-ray

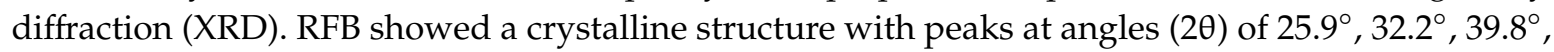
and $46.7^{\circ}$, which could be indexed as (002), (112), (310), and (222) (PDF\# 09-0432). After carbonization, the data of FBC charcoal also displayed a consistent crystalline structure, with peaks of the fishbone charcoal located at angles $(2 \theta)$ of $25.9^{\circ}, 31.8^{\circ}, 32.2^{\circ}, 39.8^{\circ}$, and $46.7^{\circ}$, which could be perfectly indexed as (002), (211), (112), (310) and (222). There may have been a small amount of graphite, however, it may have been in the amorphous phase, as observed at approximately $30^{\circ}$ for the sample FBC. After further activation, we observed that MAFC peaks located at $25.9^{\circ}, 31.8^{\circ}, 32.2^{\circ}, 39.8^{\circ}$, and $46.7^{\circ}$ could be indexed as (002), (211), (112), (310), and (222) (PDF\# 09-0432). XRD analysis of hydroxyapatite [40] presents peaks at angles $2 \theta=25.9^{\circ}, 31.9^{\circ}, 39.8^{\circ}$, and $46.4^{\circ}$. These data indicate that the main component in fishbone and fishbone charcoal was hydroxyapatite. As shown in Figure 3, the intensity of the diffraction peaks at around $2 \theta=32.2^{\circ}$ increased significantly after $\mathrm{K}_{2} \mathrm{CO}_{3}$ activation [23,41], suggesting that a well-developed calcium hydroxyphosphate skeleton structure had been fully constructed in MAFC. This may be confer MAFC excellent adsorption performance and the ability to restrain emulsified oil molecules. 


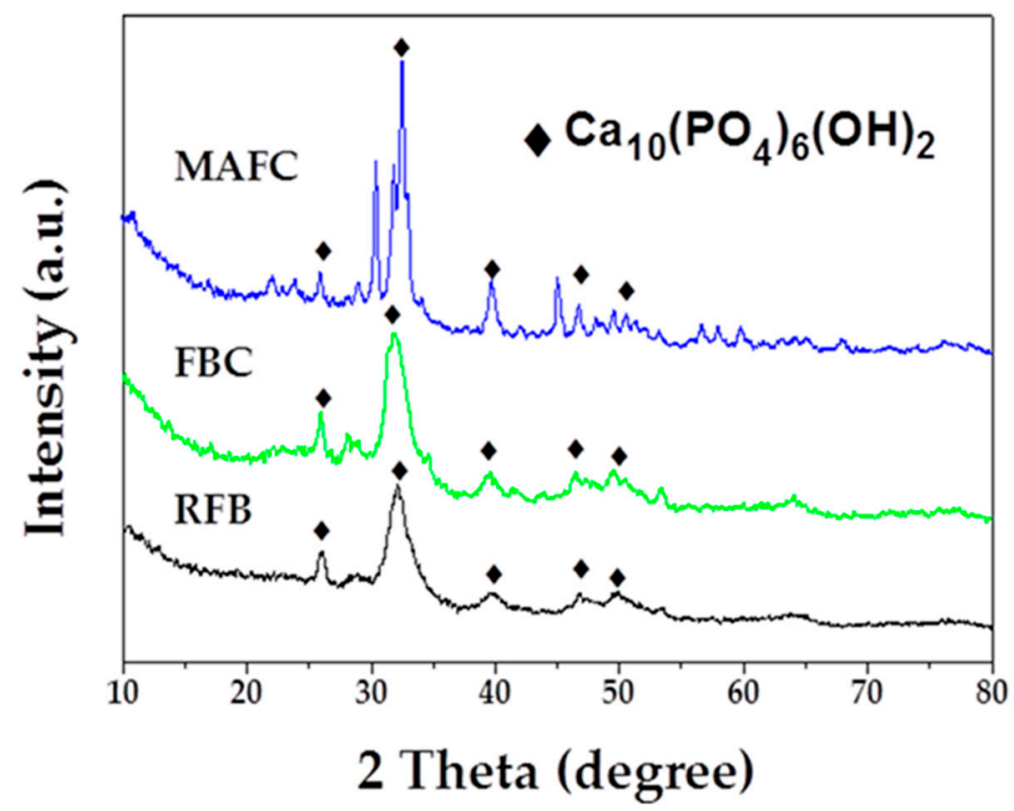

Figure 3. XRD patterns of RFB, FBC, and MAFC.

The FTIR spectra of RFB, FBC, and MAFC are illustrated in Figure 4. A broad peak at around $3450 \mathrm{~cm}^{-1}$ is observed in $\mathrm{RFB}, \mathrm{FBC}$, and MAFC, which was assigned to $\mathrm{O}-\mathrm{H}$ stretching vibration [27]. However, compared with RFB, this peak intensity was obviously reducing in both FBC and MAFC, possibly due to the loss of water and some small molecular substances. New functional groups, such as $-\mathrm{C} \equiv \mathrm{C}-\left(2201 \mathrm{~cm}^{-1}\right)$ and $-\mathrm{C}=\mathrm{N}-\left(2003 \mathrm{~cm}^{-1}\right)$, generated after pyrolysis and $\mathrm{K}_{2} \mathrm{CO}_{3}$ activation, indicating the reduction of non-polar aliphatic functional groups in fishbone biochar and the increase of the aromatization degree. Furthermore, the bands at $1450 \mathrm{~cm}^{-1}$ could be assigned to $-\mathrm{CO}_{3}-$ groups. In particular, the typical characteristic peaks of MAFC at $560 \mathrm{~cm}^{-1}, 599 \mathrm{~cm}^{-1}$, and $1025 \mathrm{~cm}^{-1}$ were attributed to $-\mathrm{PO}^{3-}$ groups [42], consistently with data previously reported for apatite-based samples [26,43-45]. Therefore, MAFC was proven to have abundant unsaturated groups. The formation of $\pi-\pi$ interactions between unsaturated groups on the surface of MAFC and aromatic rings of organic compounds, suggests a strong affinity for interaction with organic species or substances, which renders MAFC a prospect in the removal of aromatic hydrocarbons from oily wastewater.

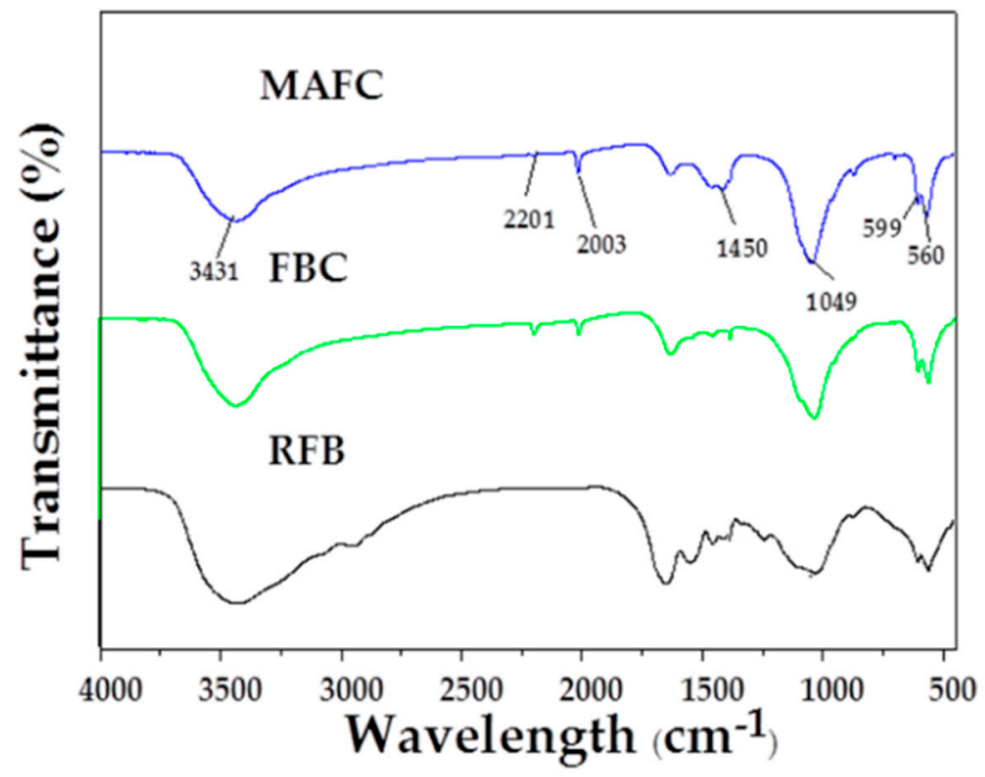

Figure 4. FTIR spectra of RFB, FBC, and MAFC. 


\subsection{Adsorption Kinetics}

The adsorption capacity of MAFC to emulsified oil over time is shown in Figure 5. The results demonstrated that emulsified oil adsorption initially increased rapidly, and the curve tended to plateau after $30 \mathrm{~min}$. Therefore, it can be inferred that the adsorption equilibrium was reached after $60 \mathrm{~min}$.

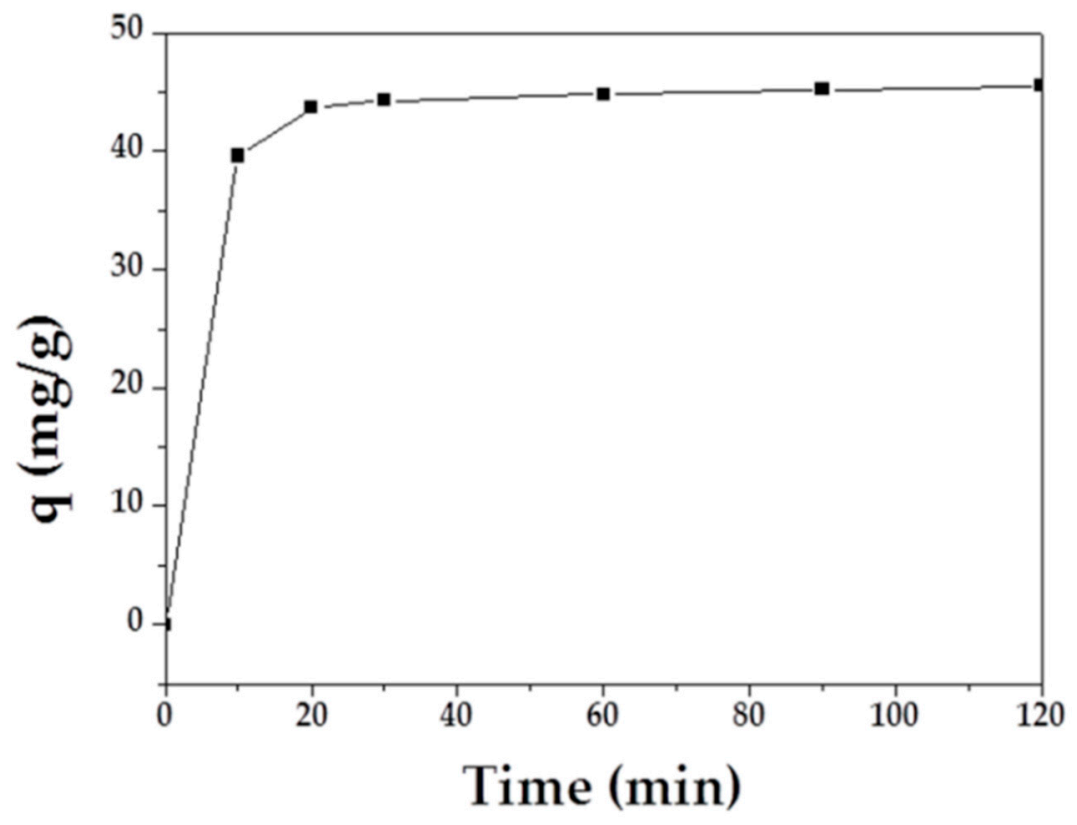

Figure 5. Effect of contact time on the adsorption of MAFC to emulsified oil.

Two main adsorption kinetics models were employed to study the adsorption mechanism of MAFC to emulsified oil. The kinetic fitting plots of the pseudo-first-order equation for the adsorption of MAFC and the kinetic fitting plots of the pseudo-second-order equation for the adsorption of MAFC are displayed in Figure 6, and some parameters used in theoretical calculation are listed in Table 2. As shown in Table 2, the correlation coefficient of the pseudo-second-order kinetics model $\left(R^{2}\right.$ $=0.99996)$ was larger than that of the first-order model $\left(\left(R^{2}=0.70651\right)\right.$, and the $\mathrm{q}_{\mathrm{e}}$ value calculated from the plot $(46.08 \mathrm{mg} / \mathrm{g})$ was closer to the actual experimental value $(45.5 \mathrm{mg} / \mathrm{g})$. Therefore, all data indicated that the second-order kinetic model was suitable for describing the real adsorption process, suggesting that the sharing or exchange of electrons between the adsorbent and the adsorbate played a dominant role in the adsorption process.

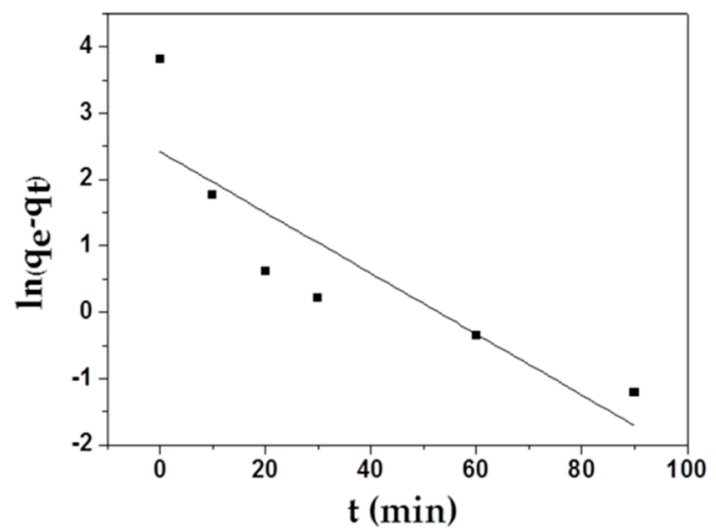

(a)

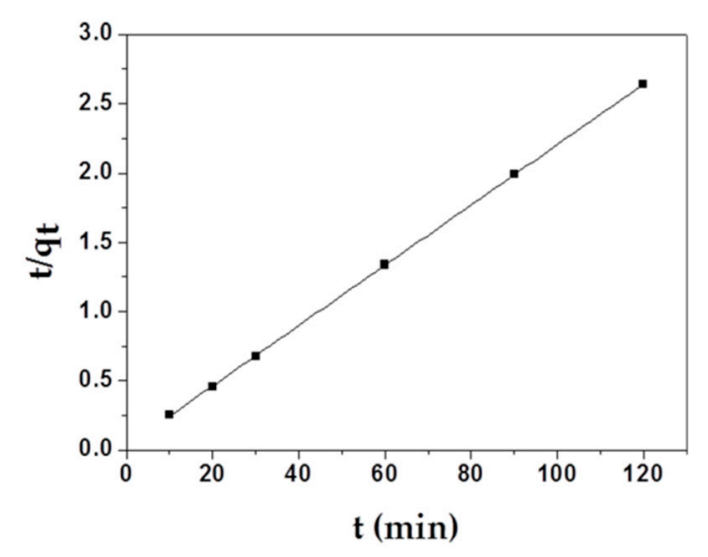

(b)

Figure 6. Kinetic fitting plots of the pseudo-first-order equation (a) for MAFC; kinetic fitting plots of the pseudo-second-order equation (b) for MAFC. 
Table 2. Constants and correlation coefficients of the isotherm and kinetics models.

\begin{tabular}{cccccc}
\hline \multicolumn{5}{c}{ Adsorption Isotherm } \\
\hline \multicolumn{7}{c}{ Langmuir Model } \\
\hline $\mathrm{q}_{\mathrm{max}}$ & $\mathrm{b}$ & $\mathrm{R}^{2}$ & $1 / \mathrm{n}$ & $\mathrm{K}_{\mathrm{f}}$ & $\mathrm{R}^{2}$ \\
100 & 0.0926 & 0.98793 & 0.386 & 15.55 & 0.93373 \\
\hline \multicolumn{7}{c}{ Kinetics Model } \\
\hline \multicolumn{7}{c}{ Pseudo-First-Order Kinetics Model } & Pseudo-Second-Order Kinetics Model \\
\hline $\mathrm{q}_{\mathrm{e}}$ & $\mathrm{K}_{1}$ & $\mathrm{R}^{2}$ & $\mathrm{q}$ & $\mathrm{K}_{2}$ & $\mathrm{R}^{2}$ \\
11.19 & 0.04 & 0.70651 & 46.08 & 0.02 & 0.99996 \\
\hline
\end{tabular}

The utilization of carbon material as an adsorbent has been well addressed. Ngarmkam and coworkers [46] carried out research on the removal and recovery of residual oil onto palm shell-based carbon; the equilibrium adsorption capacity of samples reached $30-90 \mathrm{mg} / \mathrm{g}$. Cai et al. [47] explored the adsorption properties of diesel oil on modified crab shell-activated biochar carbon; the adsorption capacity was $93.9 \mathrm{mg} / \mathrm{g}$. Although the oil sorption capacity of MAFC obtained in this experiment was $45.5 \mathrm{mg} / \mathrm{g}$, which is relatively low compared with other adsorbents, waste fish bone materials have potential to be applied for the removal of oil, at no cost.

\subsection{Adsorption Isotherms}

To estimate the adsorption capacities of as-prepared samples, two main isotherm models, Langmuir and Freundlich, were employed to study the adsorption isotherm process of MAFC to emulsified oil, as illustrated in Figure 7. As shown in Table 2, Langmuir isotherm (correlation coefficients $\mathrm{R}^{2}=0.98793$ ) correlates better with the actual adsorption process than Freundlich isotherm (correlation coefficients $R^{2}=0.93373$ ). The non-dimensional separation factor $R_{L}$ was 0.0975 , in the range of $0<\mathrm{R}_{\mathrm{L}}<1$, indicating that the adsorption of MAFC to emulsified oil in the studied concentration range was consistent with the Langmuir adsorption isotherm. In addition, the Freundlich isotherm model constant $\mathrm{n}$ was in the range of 1-10, indicating that MAFC was effective in the adsorption of emulsified oil, and the adsorption process was dominated by physical adsorption [35]. Meanwhile, the value of $1 / \mathrm{n}$ was $0.386(1 / \mathrm{n}<1)$, indicating that $38.6 \%$ of the active sites had the same energy level, and the adsorption process could be described by the standard Freundlich isotherm. However, the adsorption process might have a multi-layer adsorption mechanism with a small linear correlation coefficient.
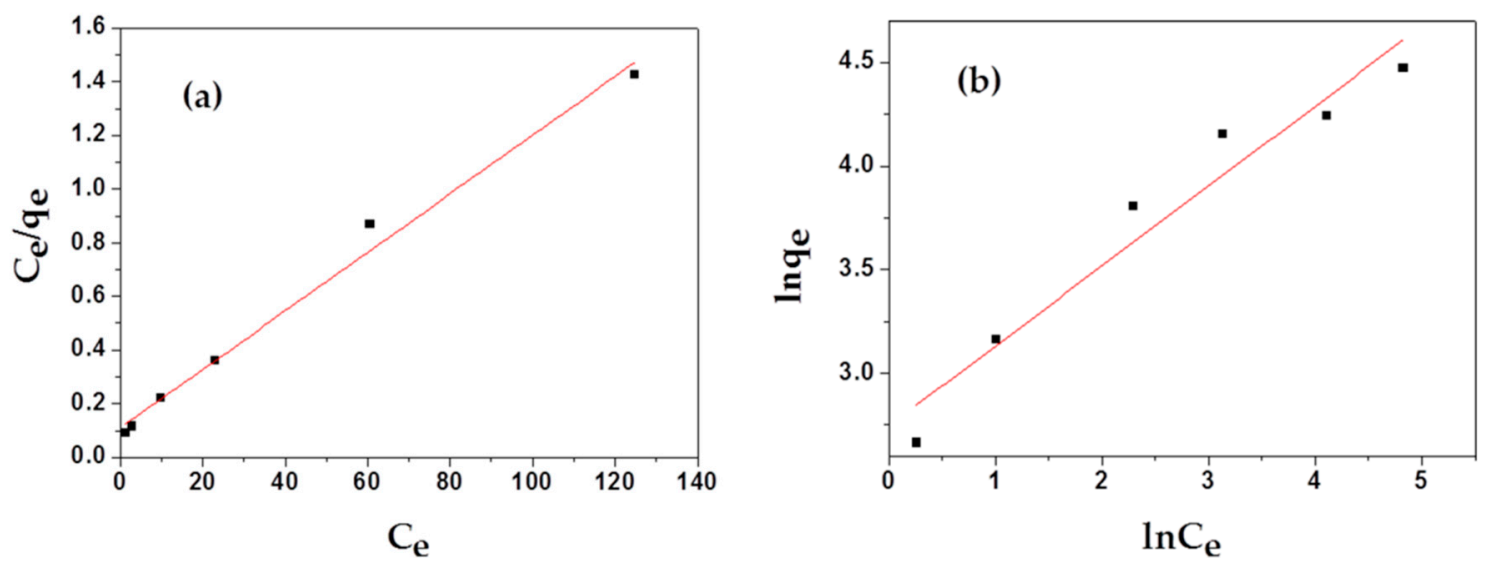

Figure 7. Langmuir (a) and Freundlich (b) isotherms for the adsorption of MAFC to emulsified oil.

\subsection{Effect of Adsorbent Dose}

The effect of the adsorbent dose on the adsorption of MAFC to emulsified oil is seen in Figure 8. The adsorption capacity gradually decreased with the increase of adsorbent dosage, while the adsorption 
rate gradually increased and then tended to be stable. This is because more surface active functional groups were available with a greater dose of adsorbent, which could result in a higher adsorption rate. However, the adsorption efficiency was limited by the constant initial emulsified oil concentration. As shown in Figure 8, the adsorption rate of around $90.1 \%$ tended to be stable with $0.1 \mathrm{~g}$ adsorbent added in $100 \mathrm{mg} / \mathrm{L}$ oily wastewater, and the adsorption capacity reduced to $45.05 \mathrm{mg} / \mathrm{g}$. Therefore, we could choose $0.1 \mathrm{~g}$ as an optimum dose for MAFC.

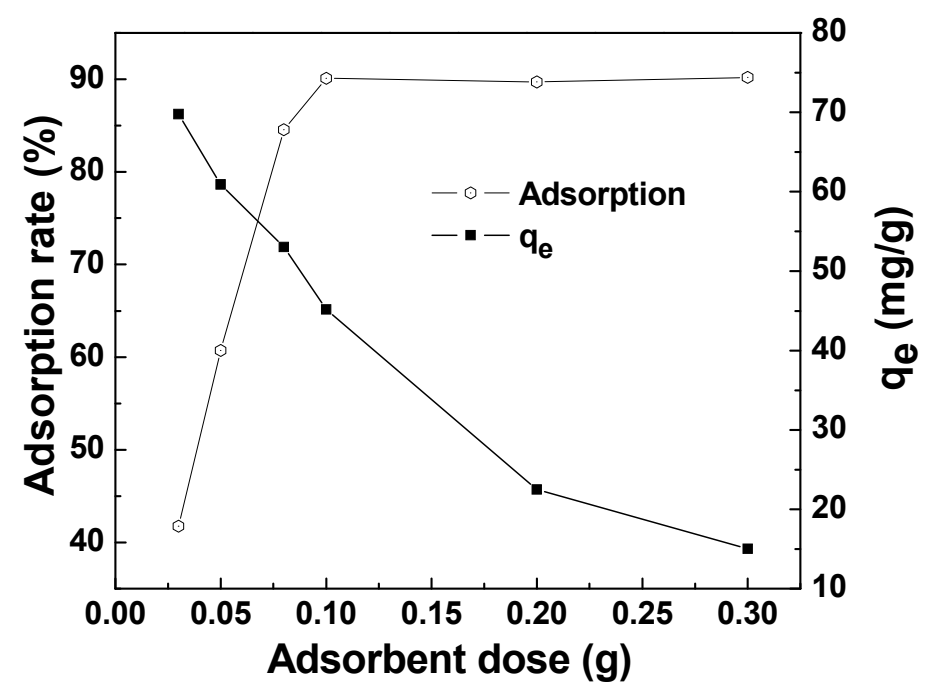

Figure 8. Effect of adsorbent dose on the adsorption of MAFC to emulsified oil (emulsified oil $100 \mathrm{mg} / \mathrm{L}$, contact time $30 \mathrm{~min}$, reaction temperature $25^{\circ} \mathrm{C}$ ).

\subsection{Effect of Reaction Temperature}

The effect of reaction temperature on the adsorption of MAFC to emulsified oil (100 $\mathrm{mg} / \mathrm{L})$ is illustrated in Figure 9. The maximum adsorption capacity and adsorption rate of MAFC were obtained at $25{ }^{\circ} \mathrm{C}(45 \mathrm{mg} / \mathrm{g})$. The test data showed that the adsorption efficiency decreased with the increase of the reaction temperature. The increase in the desorption rate of emulsified oil was due to the increase of intramolecular thermal movement speed. In addition, adsorption is an exothermic process, and the increase of the reaction temperature will inhibit the adsorption process. Therefore, it is advisable to choose $25^{\circ} \mathrm{C}$ as the optimum adsorption temperature.

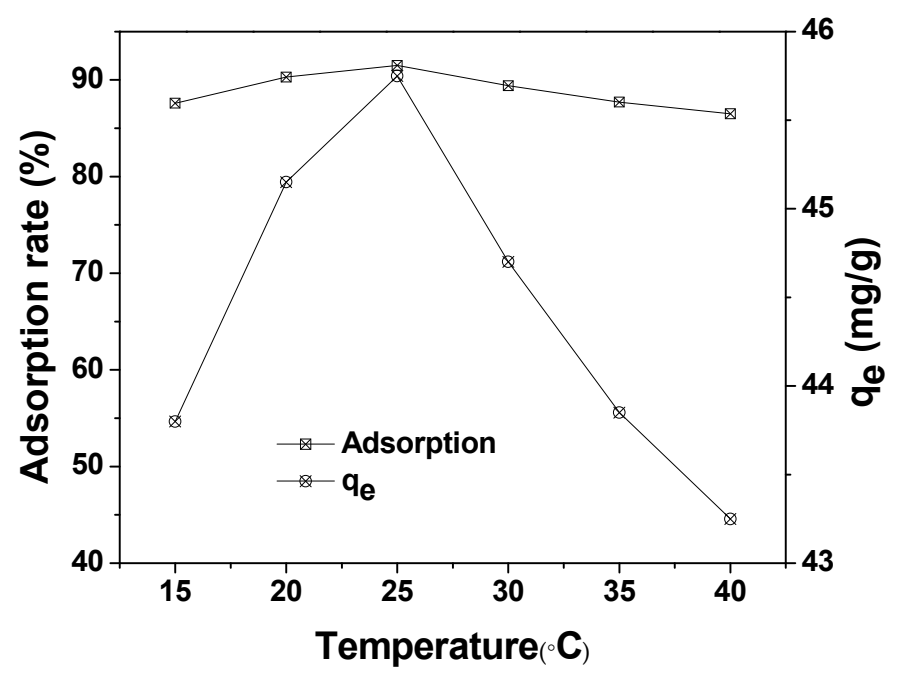

Figure 9. Effect of reaction temperature on the adsorption of MAFC to emulsified oil (emulsified oil $100 \mathrm{mg} / \mathrm{L}$, contact time $30 \mathrm{~min}$, and MAFC $0.1 \mathrm{~g}$ ). 


\subsection{Recyclability Studies}

For the practical application of MAFC, its recycling performance and its efficiency were estimated. As shown in Figure 10, the adsorption capacity of MAFC to emulsified oil was measured for six testing cycles (each cycle for $60 \mathrm{~min}$ ). In the first cycle, $45.15 \mathrm{mg} / \mathrm{g}$ of emulsified oil was adsorbed, and after all cycles, this adsorption capacity of MAFC still reached $20 \mathrm{mg} / \mathrm{g}$, indicating that MAFC has the stability and efficiency to be used as a good adsorbent.

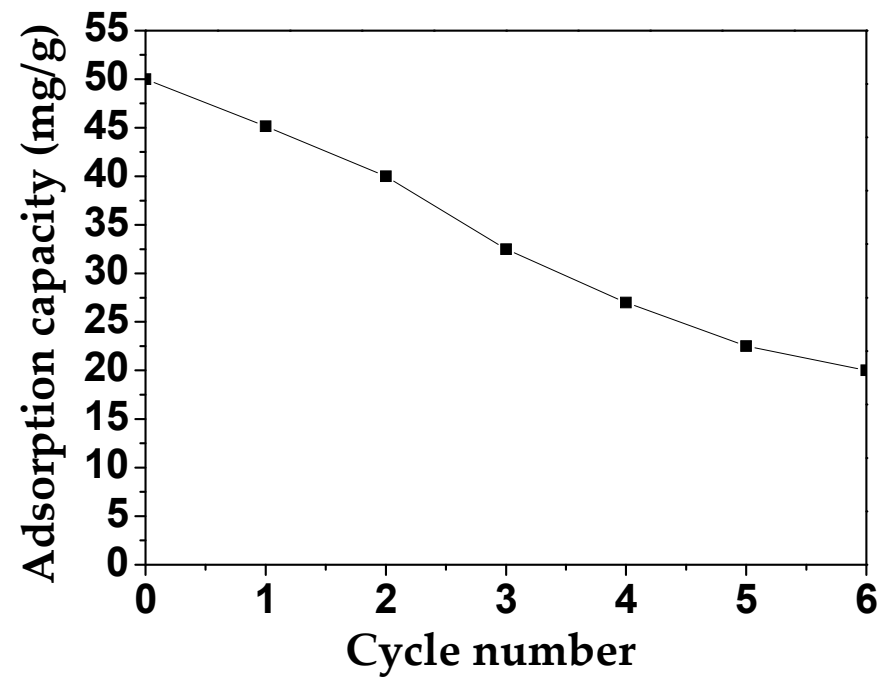

Figure 10. Determination of the recyclability of MAFC based on the adsorption rate of emulsified oil.

\section{Conclusions}

A promising charcoal nanomaterial was successfully prepared from fishbone waste. In this work, MAFC exhibited an excellent performance for removing emulsified oil under various experimental conditions. Although the specific surface area of MAFC was relatively small, i.e., $206.0 \mathrm{~m}^{2} / \mathrm{g}$, compared with other adsorbent materials, its removal rate of emulsified oil could reach $90.1 \%$, which was attributed to the presence of abundant active sites, which were fully exposed after modification by $\mathrm{K}_{2} \mathrm{CO}_{3}$ activation. In addition, excellent HAp crosslinked structures with well-developed porous structures could also increase the adsorption efficiency of MAFC. Therefore, this low-cost, effective, and recyclable charcoal nanomaterial could be a promising bio-adsorbent of organic pollutants in oily wastewater.

Author Contributions: W.S., L.J. and H.Z. conceived and designed the experiments; Y.W., Y.Z. and L.C. conducted the experiments; W.S., L.J. and Y.Z. discussed the results; J.G. was responsible for Funding acquisition; Y.Z. and H.Z. wrote the manuscript; Y.X. conducted Visualization and Validation.

Funding: This research was funded by the Natural Science Foundation of Zhejiang Province, China, grant number: LQ16D060004; and this research was also supported by the Key Research and Development Projects of Zhejiang Province, China (No. 2018C02043).

Acknowledgments: This study was supported by the Demonstration Project of Marine Economic Innovation and Development of Zhoushan City of China, and the Demonstration Project of Marine Economic Innovation and Development of Yantai City of China (No. YHCX-SW-L-201705).

Conflicts of Interest: The authors declare no conflict of interest.

\section{References}

1. Li, Y.; Wang, M.; Sun, D.; Li, Y.; Wu, T. Effective removal of emulsified oil from oily wastewater using surfactant-modified sepiolite. Appl. Clay. Sci. 2018, 157, 227-236. [CrossRef] 
2. Yi, G.; Chen, S.; Quan, X.; Wei, G.; Fan, X.; Yu, H. Enhanced separation performance of carbon nanotube-polyvinyl alcohol composite membranes for emulsified oily wastewater treatment under electrical assistance. Sep. Purif. Technol. 2018, 197, 107-115. [CrossRef]

3. Li, C.; Song, C.; Tao, P.; Sun, M.; Pan, Z.; Wang, T.; Shao, M. Enhanced separation performance of coal-based carbon membranes coupled with an electric field for oily wastewater treatment. Sep. Purif. Technol. 2016, 168, 47-56. [CrossRef]

4. Qiao, L.; Wen, D.H.; Wang, J.L. Biodegradation of pyridine by Paracoccus sp. KT-5 immobilized on bamboo-based activated carbon. Bioresour. Technol. 2010, 101, 5229-5234.

5. Li, J.; Cai, W.J.; Cai, J.J. The characteristics and mechanisms of pyridine biodegradation by Streptomyces sp. J. Hazard. Mater. 2009, 165, 950. [CrossRef] [PubMed]

6. Chen, Y.; Yu, B.; Lin, J.; Naidu, R.; Chen, Z. Simultaneous adsorption and biodegradation (SAB) of diesel oil using immobilized Acinetobacter venetianus, on porous material. Chem. Eng. J. 2016, 289, 463-470. [CrossRef]

7. Wang, X.; Wang, X.; Liu, M.; Bu, Y.; Zhang, J.; Chen, J.; Zhao, J. Adsorption-synergic biodegradation of diesel oil in synthetic seawater by acclimated strains immobilized on multifunctional materials. Mar. Pollut. Bull. 2015, 92, 195-200. [CrossRef]

8. Cheryan, M.; Rajagopalan, N. Membrane processing of oily streams. Wastewater treatment and waste reduction. J. Membr Sci. 2015, 151, 13-28. [CrossRef]

9. Al-Yaari, M.; Hussein, I.A.; Al-Sarkhi, A. Pressure drop reduction of stable water-in-oil emulsions using organoclays. Appl. Clay. Sci. 2014, 95, 303-309. [CrossRef]

10. Altmann, J.; Ruhl, A.S.; Zietzschmann, F.; Jekel, M. Direct comparison of ozonation and adsorption onto powdered activated carbon for micropollutant removal in advanced wastewater treatment. Water Res. 2014, 55, 185-193. [CrossRef]

11. Enniya, I.; Rghioui, L.; Jourani, A. Adsorption of hexavalent chromium in aqueous solution on activated carbon prepared from apple peels. Sustain. Chem. Pharm. 2018, 7, 9-16. [CrossRef]

12. Lee, D.J.; Cheng, Y.L.; Wong, R.J.; Wang, X.D. Adsorption removal of natural organic matters in waters using biochar. Bioresour. Technol. 2018, 260, 413-416. [CrossRef] [PubMed]

13. Ghosh, S.K.; Bandyopadhyay, A. Adsorption of methylene blue onto citric acid treated carbonized bamboo leaves powder: Equilibrium, kinetics, thermodynamics analyses. J. Mol. Liq. 2017, 248, 413-424. [CrossRef]

14. Jian, X.; Zhuang, X.; Li, B.; Xu, X.; Wei, Z.; Song, W.; Jiang, E. Comparison of characterization and adsorption of biochars produced from hydrothermal carbonization and pyrolysis. Environ. Technol. Innovat. 2018, 10, 27-35. [CrossRef]

15. Yang, K.; Jiang, Y.; Yang, J. Correlations and adsorption mechanisms of aromatic compounds on biochars produced from various biomass at $700{ }^{\circ} \mathrm{C}$. Environ. Pollut. 2017, 233, 64. [CrossRef] [PubMed]

16. Fan, S.; Tang, J.; Wang, Y.; Li, H.; Zhang, H.; Tang, J.; Wang, Z.; Li, X. Biochar prepared from co-pyrolysis of municipal sewage sludge and tea waste for the adsorption of methylene blue from aqueous solutions: Kinetics, isotherm, thermodynamic and mechanism. J. Mol. Liq. 2016, 220, 432-441. [CrossRef]

17. Zhang, M.; Gao, B. Removal of arsenic, methylene blue, and phosphate by biochar/AlOOH nanocomposite. Chem. Eng. J. 2013, 226, 286-292. [CrossRef]

18. Ahmad, W.; Ahmad, I.; Ishaq, M.; Ihsan, K. Adsorptive desulfurization of kerosene and diesel oil by Zn impregnated montmorollonite clay. Arab. J. Chem. 2014, 50, 543-549. [CrossRef]

19. Prajapati, Y.N.; Verma, N. Adsorptive desulfurization of diesel oil using nickel nanoparticle-doped activated carbon beads with/without carbon nanofibers: Effects of adsorbate size and adsorbent texture. Fuel 2017, 189, 186-194. [CrossRef]

20. Reynolds, J.G.; Coronado, P.R.; Hrubesh, L.W. Hydrophobic Aerogels for Oil-Spill Cleanup? Intrinsic Absorbing Properties. Energy Sour. 2001, 23, 831-843.

21. Anastopoulos, G. Investigation of the effectiveness of absorbent materials in oil spills clean up. Desalination 2001, 140, 259-264.

22. Adebajo, M.O.; Frost, R.L.; Kloprogge, J.T.; Carmody, O.; Kokot, S. Porous materials for oil spill cleanup: A review of synthesis and absorbing properties. J. Porous Mater. 2003, 10, 159-170. [CrossRef]

23. Piccirillo, C.; Moreira, I.S.; Novais, R.M.; Fernandes, A.J.S.; Pullar, R.C.; Castro, P.M.L. Biphasic apatite-carbon materials derived from pyrolysed fish bones for effective adsorption of persistent pollutants and heavy metals. J. Environ. Chem. Eng. 2017, 5, 4884-4894. [CrossRef] 
24. Lim, H.K.; Teng, T.T.; Ibrahim, M.H.; Ahmad, A.; Chee, H.T. Adsorption and removal of zinc (ii) from aqueous solution using powdered fish bones. Apcbee. Procedia 2012, 1, 96-102. [CrossRef]

25. Mobasherpour, I.; Salahi, E.; Pazouki, M. Comparative of the removal of $\mathrm{Pb}^{2+}, \mathrm{Cd}^{2+}$, and $\mathrm{Ni}^{2+}$, by nano crystallite hydroxyapatite from aqueous solutions: Adsorption isotherm study. Arab. J. Chem. 2012, 5, 439-446. [CrossRef]

26. Goto, T.; Sasaki, K. Effects of trace elements in fish bones on crystal characteristics of hydroxyapatite obtained by calcinations. Ceram. Int. 2014, 40, 10777-10785. [CrossRef]

27. Wang, W.; Liu, Y.; Song, S.; Cai, W. Facile pyrolysis of fishbone charcoal with remarkable adsorption performance towards aqueous pb (ii). J. Environ. Chem. Eng. 2017, 5, 4621-4629. [CrossRef]

28. Zayed, E.M.; Sokker, H.H.; Albishri, H.M.; Farag, A.M. Potential use of novel modified fishbone for anchoring hazardous metal ions from their solutions. Ecol. Eng. 2013, 61, 390-393. [CrossRef]

29. Liu, Z.; Zhang, F.; Liu, T.; Peng, N.; Gai, C. Removal of azo dye by a highly graphitized and heteroatom doped carbon derived from fish waste: adsorption equilibrium and kinetics. J. Environ. Manag. 2016, 182, 446-454. [CrossRef]

30. Adinata, D.; Wan, D.W.; Aroua, M.K. Preparation and characterization of activated carbon from palm shell by chemical activation with $\mathrm{K}_{2} \mathrm{CO}_{3}$. Bioresour. Technol. 2007, 98, 145-149. [CrossRef]

31. Guo, J.; Lua, A.C. Textural and chemical properties of adsorbent prepared from palm shell by phosphoric acid activation. Mater. Chem. Phys. 2003, 80, 114-119. [CrossRef]

32. Lua, A.C.; Yang, T. Effect of activation temperature on the textural and chemical properties of potassium hydroxide activated carbon prepared from pistachio-nut shell. J. Colloid. Interface Sci. 2004, 274, 594-601. [CrossRef]

33. Foo, K.Y.; Hameed, B.H. Porous structure and adsorptive properties of pineapple peel based activated carbons prepared via microwave assisted $\mathrm{KOH}$ and $\mathrm{K}_{2} \mathrm{CO}_{3}$, activation. Microporous Mesoporous Mater. 2012, 148, 191-195. [CrossRef]

34. Raymundo-Pinero, E.; Azais, P.; Cacciaguerra, T.; Cazorla-Amorós, D.; Linares-Solano, A.; Béguin, F. KOH and $\mathrm{NaOH}$ activation mechanisms of multiwalled carbon nanotubes with different structural organisation. Carbon 2005, 43, 786-795. [CrossRef]

35. Angin, D. Utilization of activated carbon produced from fruit juice industry solid waste for the adsorption of Yellow 18 from aqueous solutions. Bioresour. Technol. 2014, 168, 259-266. [CrossRef]

36. Wang, X.; Wang, J.; Zhang, J.; Louangsouphom, B.; Zhao, J. Synthesis of expanded graphite C/C composites (EGC) based $\mathrm{Ni}-\mathrm{N}-\mathrm{TiO}_{2}$ floating photocatalysts for in situ adsorption synergistic photocatalytic degradation of diesel oil. J. Photochem. Photobiol. A: Chem. 2017, 347, 105-115. [CrossRef]

37. Foo, K.Y.; Hameed, B.H. Factors affecting the carbon yield and adsorption capability of the mangosteen peel activated carbon prepared by microwave assisted $\mathrm{K}_{2} \mathrm{CO}_{3}$ activation. Chem. Eng. J. 2012, 180, 66-74. [CrossRef]

38. Mckee, D.W. Mechanisms of the alkali metal catalysed gasification of carbon. Fuel 1983, 62, $170-175$. [CrossRef]

39. Tay, T.; Ucar, S.; Karagöz, S. Preparation and characterization of activated carbon from waste biomass. J. Hazard. Mater. 2009, 165, 481-485. [CrossRef]

40. Lazarević, S.; Janković-Častvan, I.; Tanasković, D.; Pavićević, V.; Janaćković, D.; Petrović, R. Sorption of Pb ${ }^{2+}$, $\mathrm{Cd}^{2+}$, and $\mathrm{Sr}^{2+}$ ions on calcium hydroxyapatite powder obtained by the hydrothermal method. J. Environ. Eng. 2008, 134, 683-688. [CrossRef]

41. Niimi, M.; Masuda, T.; Kaihatsu, K.; Kato, N.; Nakamura, S.; Nakaya, T.; Arai, F. Virus purification and enrichment by hydroxyapatite chromatography on a chip. Sens. Actuators. B: Chem. 2014, 201, 185-190. [CrossRef]

42. Wang, W.; Liu, Y.Y.; Chen, X.F.; Song, S.X. Facile synthesis of NaOH-modified fishbone charcoal (FBC) with remarkable adsorption towards methylene blue. Procedia Eng. 2018, 211, 495-505. [CrossRef]

43. Swain, S.K.; Dorozhkin, S.V.; Sarkar, D. Synthesis and dispersion of hydroxyapatite nanopowders. Mater. Sci. Eng. C 2012, 32, 1237-1240. [CrossRef]

44. Zhou, J.; Sui, Z.; Zhou, X.; Yuan, W. Palladium catalysts supported on fishbone carbon nanofibers from different carbon sources. Chin. J. Cat. 2008, 29, 1107-1112. [CrossRef]

45. Yue, M.; Saffarzadeh, A.; Shimaoka, T. Feasibility of Using Natural Fishbone Apatite on Removal of Pb from Municipal Solid Waste Incineration (MSWI) Fly Ash. Procedia Environ. Sci. 2016, 31, 345-350. 
46. Ngarmkam, W.; Sirisathitkul, C.; Phalakornkule, C. Magnetic composite prepared from palm shell-based carbon and application for recovery of residual oil from POME. J. Environ. Manag. 2011, 92, 472-479. [CrossRef]

47. Cai, L.; Zhang, Y.; Zhou, Y.; Zhang, X.; Ji, L.; Song, W.; Zhang, H.; Liu, J. Effective Adsorption of Diesel Oil by Crab-Shell-Derived Biochar Nanomaterials. Materials 2019, 12, 236. [CrossRef] 